\title{
2D Idealisation of Hollow Reinforced Concrete Beams Subjected to Combined Torsion, Bending and Shear
}

\author{
A.S. Al-Nuaimi ${ }^{* 1}$ and P. Bhatt ${ }^{2}$ \\ ${ }^{1}$ Department of Civil and Architectural Engineering, College of Engineering, Sultan Qaboos University, P.O. Box 33, Al-Khodh \\ 123, Muscat, Sultanate of Oman \\ ${ }^{2}$ Honorary Senior Research Fellow, Department of Civil Engineering, Glasgow University, Glasgow, G12 8QQ, UK
}

Received 1 June 2004; accepted 4 September 2004

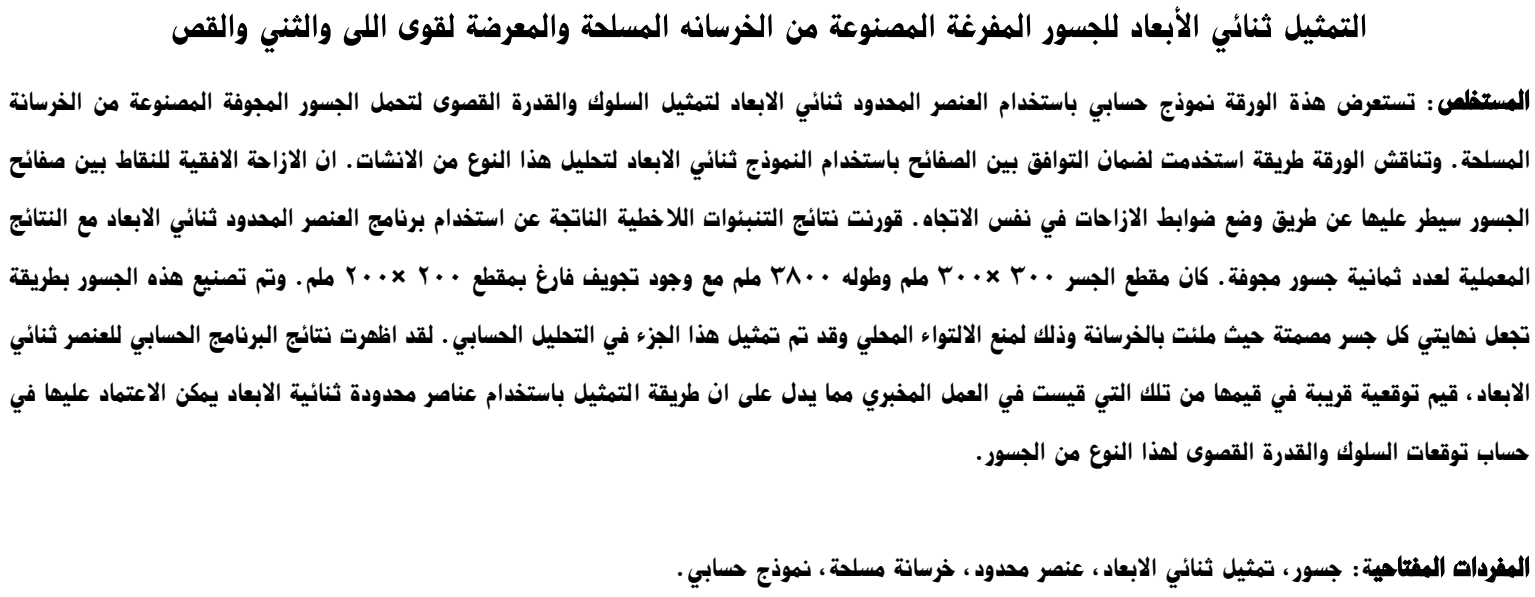

\begin{abstract}
This paper presents a finite element model for idealisation of reinforced concrete hollow beams using 2D plane elements. The method of ensuring compatibility between the plates using two-dimensional model to analyze this type of structures is discussed. Cross-sectional distortion was minimised by incorporating end diaphragms in the FE model. Experimental results from eight reinforced concrete hollow beams are compared with the non-linear predictions produced by a 2D in-house FE program. The beam dimensions were $300 \times 300 \mathrm{~mm}$ cross section with $200 \times 200 \mathrm{~mm}$ hollow core and $3800 \mathrm{~mm}$ long. The beam ends were filled with concrete to form solid end diaphragms to prevent local distortion. The beams were subjected to combined bending, torsion and shear. It was found that the two-dimensional idealisation of hollow beams is adequate provided that compatibility of displacements between adjoining plates along the line of intersection is maintained and the cross-sectional distortion is reduced to minimum. The results from the 2D in-house finite element program showed a good agreement with experimental results.
\end{abstract}

Keywords: 2D analysis, Finite element method, Hollow beams, Bending, Torsion, Shear, Combined load, Numerical model

\section{Notation}

$B=$ The strain matrix composed of derivatives of shape functions

$D \quad=$ The elasticity matrix

$\{F\} \quad=$ The equivalent nodal forces for the continuum

$E_{c} \quad=$ The initial modulus of elasticity of concrete for uniaxial loading.

$E_{s} \quad=$ The secant modulus of elasticity at peak stress $E_{s}=\sigma_{p} / \varepsilon_{p}$

$f_{c u}=$ Concrete cube compressive strength

$f_{c}=$ Concrete cylinder compressive strength

$f_{t}{ }^{\prime} \quad=$ Tensile strength of concrete

$\left\{F_{i}\right\}=$ The total applied load vector

*Corresponding authors E-mail: alnuaimi@squ.edu.om 
The Journal of Engineering Research Vol. 2, No. 1 (2005) 53-68

$\mathrm{L}_{\mathrm{c}} \quad=$ Computational failure load $=\left(\mathrm{M}_{\mathrm{c}}+\mathrm{T}_{\mathrm{c}}\right) / 2$

$\mathrm{L}_{\mathrm{d}} \quad=$ Design ultimate load $=\left(\mathrm{M}_{\mathrm{d}}+\mathrm{T}_{\mathrm{d}}\right) / 2$

$\mathrm{L}_{\mathrm{e}} \quad=$ Experimental failure load $=\left(\mathrm{M}_{\mathrm{e}}+\mathrm{T}_{\mathrm{e}}\right) / 2$

L.F. $\quad=$ Load factor

L.F. $\quad=\left(\mathrm{M}_{\mathrm{e}} / \mathrm{M}_{\mathrm{d}}+\mathrm{T}_{\mathrm{e}} / \mathrm{T}_{\mathrm{d}}\right) / 2$

$\mathrm{M}_{\mathrm{d}}, \mathrm{T}_{\mathrm{d}}, \mathrm{V}_{\mathrm{d}}=$ Design ultimate bending moment, twisting moment and shear force, respectively

$\mathrm{M}_{\mathrm{e}}, \mathrm{T}_{\mathrm{e}}, \mathrm{V}_{\mathrm{e}}=$ Experimental failure bending, torsion and shear force, respectively

$\mathrm{M}_{\mathrm{c}}, \mathrm{T}_{\mathrm{c}}, \mathrm{V}_{\mathrm{c}}=$ Computed failure bending, torsion and shear force, respectively

$\left\{R_{i}\right\} \quad=$ The residual force vector at $\mathrm{i}_{\text {th }}$ iteration

$\alpha \quad=$ The ratio of the principal stresses $\sigma_{2} / \sigma_{1}$

$\{\delta\} \quad=$ The nodal displacements of the continuum

$\varepsilon_{c c} \quad=$ Concrete strain at peak stress

$\varepsilon_{c r} \quad=$ The tensile crack strain (corresponds to the peak tensile stress)

$\varepsilon_{\max } \quad=$ Maximum compressive strain

$\varepsilon_{n} \quad=$ A fictitious strain normal to the crack plane

$\varepsilon_{p} \quad=$ The strain at the peak (maximum) compressive stress of the concrete $\sigma_{p}$

$\varepsilon / \varepsilon_{y} \quad=$ Steel strain ratio $=$ Measured strain at L.F. load $/$ Measured yield strain

$v \quad=$ The Poisson's ratio

$\sigma$ and $\varepsilon=$ The current stress and strain

$\sigma_{p} \quad=$ The ultimate strength of concrete in compression, equal $f_{C}$ '

$\tau_{\text {tor }} \quad=$ Shear stress due torsion

$\tau_{\text {shr }} \quad=$ Shear stress due shear force.

\section{Introduction}

Considering the complex behaviour of hollow beams, a detailed analysis would normally require a full threedimensional finite element model especially with box-sections for large girder bridges. However, a study of the structural behaviour of typical thin-walled concrete beams indicates that the main stress conditions are those of direct stresses in the plates of the box beam. The forces involved in out-of-plane bending are very small and can be ignored. The distortion of cross-section is prevented by the use of reasonably thick plates and end diaphragms. This suggests that the main stresses are in-plane ones and, therefore, plane stress elements can be used to account for the major stresses. Zero stiffness is assumed for out-of-plane bending action of the component plates. Figure 1 shows the state of stress in a typical box beam subjected to bending, torsion and shear. The wall thickness used for torsional resistance was $50 \mathrm{~mm}$ which is $1 / 6$ of the beam depth (Thurliman, 1979; MacGregor and Ghoneim, 1995).

Bhatt and Beshara (1980) studied the behaviour of bridge box girders using similar method with plane elements. In their work, out of plane bending was considered due to the large size of the box girder. The advantages of using 2D approach over a full 3D finite elements solution as studied by Abdel-Kader (1993) is that it is easier and leads to cheaper computations while at the same time the main stresses are obtained with reasonable accuracy. In this study, a 2D in-house finite element program was used to analyse eight reinforced concrete box beams. The actual beam ends were filled with concrete to form end diaphragms. The diaphragms were included in the numerical analysis. The predicted behaviour was compared with the experimental results.

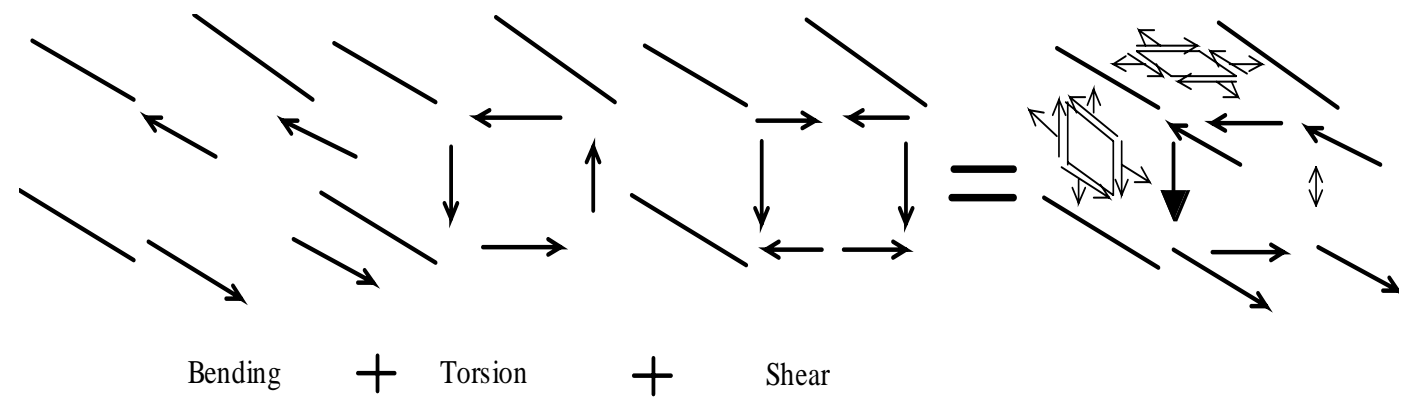

Figure 1. State of stress in a typical beam 


\section{Research Significance}

A method using 2D plane elements to model 3D hollow beams is introduced. The compatibility of displacement between adjoining plates was maintained by introducing constraints on the displacement. The cross-sectional distortion was minimized by incorporating the end diaphragms into the in-house FE program. This work is restricted to the analysis of hollow cross-sections with inplane stresses.

\section{Geometrical Relationship between Displacements}

The two-dimensional idealisation of box girders is adequate provided compatibility of displacement between adjoining plates along the line of intersection is maintained and cross-sectional distortion is reduced to a minimum. To achieve these objectives, the following steps were adopted as shown in Fig. 2:

1. To ensure shear transfer between adjoining plates of the beam, compatibility of displacement along the line of intersection at the common edge of adjoining plates is maintained by introducing geometrical constraints.

2. To reduce cross-sectional distortion, end diaphragms are introduced into the analysis.

To illustrate this technique, consider top flange, front web and left diaphragm of a typical beam as shown in Fig. 3. For ease, only corner nodes of some elements are shown in this illustration.

If the out-of-plane bending is ignored, then the web and the flange can be considered as thin plates in a state of plane stress. However, the displacements of both plates along the joining line are equal to each other. The displacements perpendicular to the joining line are independent of each other. The same applies to the lines joining the plates with the diaphragm. It is therefore, necessary in this analysis to enforce geometrical constraints to ensure compatibility along the lines of intersections. This is done by giving the same freedom number for those equal displacements. Other freedoms which are independent are given different numbers. In other words, every pair of displacements in the $\mathrm{x}$-direction (direction of the beam axis) of the joining line between the flange and the web will be having the same freedom number and, therefore, the same displacement value for that pair. The displacements perpendicular to this line will have different numbers. In addition to the freedom numbering, attention should be given to plate orientation when the whole structure is assembled, to prevent contradicting directions of displacements. The rigid body movement is prevented by proper restraints, which are dependent on the load conditions and support locations.

\section{A 2-D Finite Element Program}

In modelling the linear and non-linear responses of concrete as a continuum, the non-linear elasticity approach was adopted. In this approach, the bulk modulus, shear modulus, Poisson's ratio and Young's modulus of concrete are expressed in terms of stress/strain variables, such as deviatoric stresses or strains, stress or strain invariants, normal and octahedral strain ... etc. The moduli were used to formulate an isotropic matrix to represent the behaviour of concrete at a certain load level (Alnuaimi, 1999; Kotsovos and Pavlovic, 1995; Chen and Saleeb, 1994). No bar dual action or bar kinking were included in the analysis.

The above idealisation was implemented in a 2D finite element program originally developed for carrying out non-linear analysis of solid rectangular beams AbdelKader, (1993). In this program, Eq. 1 was used to represent the ascending portion of the uniaxial compressive stress-strain curve. This equation was tested by Darwin and Pecknold, (1977) on many experimental results and used by Bhatt and Abdel-Kader, (1995) to numerically analyse many reinforced and pre-stressed concrete beams from different experimental investigations.

$$
\sigma=\frac{E_{c} \cdot \varepsilon}{1+\left(\frac{E_{c}}{E_{s}}-2\right) \frac{\varepsilon}{\varepsilon_{p}}+\left(\frac{\varepsilon}{\varepsilon_{p}}\right)^{2}}
$$

In modelling the non-linear stress-strain relationship of the concrete in the principle stress direction, Eq. (2) was adopted as proposed by Liu et al. (1972) and used by Bhatt and Abdel-Kader, (1995). This equation accounts for non-linear behaviour of concrete in biaxial compression and takes the form:

$$
\sigma=\frac{E_{c}^{\prime} \cdot \varepsilon}{(1-v \alpha)\left[1+\left(\frac{1}{1-v \alpha} \frac{E_{c}}{E_{s}}-2\right) \frac{\varepsilon}{\varepsilon_{p}}+\left(\frac{\varepsilon}{\varepsilon_{p}}\right)^{2}\right]}
$$

If $\alpha=0$, i.e. for uniaxial state of stress, Eqs. (1) and (2) become identical.

Equation (2) was used to generate the stress-strain behaviour of concrete in biaxial compression up to peak strain $\varepsilon_{p}$, after which this equation ceases to be valid due to softening deformation. A linear descending curve was adopted by Bhatt and Abdel Kader (1995) as given by Eq. (3) after the maximum stress was reached until a maximum strain of 0.0035 after which the stress drops to zero.

$\sigma=\frac{(0.1-\varepsilon)}{\left(0.1-\varepsilon_{c c}\right)} f_{c}^{\prime} \quad \varepsilon<0.0035$

Figure 4 shows typical stress-strain curve for combined ascending and descending parts plotted using Eqs. (1) and (3).

Smeared crack model with orthogonal cracks was adopted. In this model, it is assumed that before cracking the concrete is a homogeneous, isotropic and linear elastic 


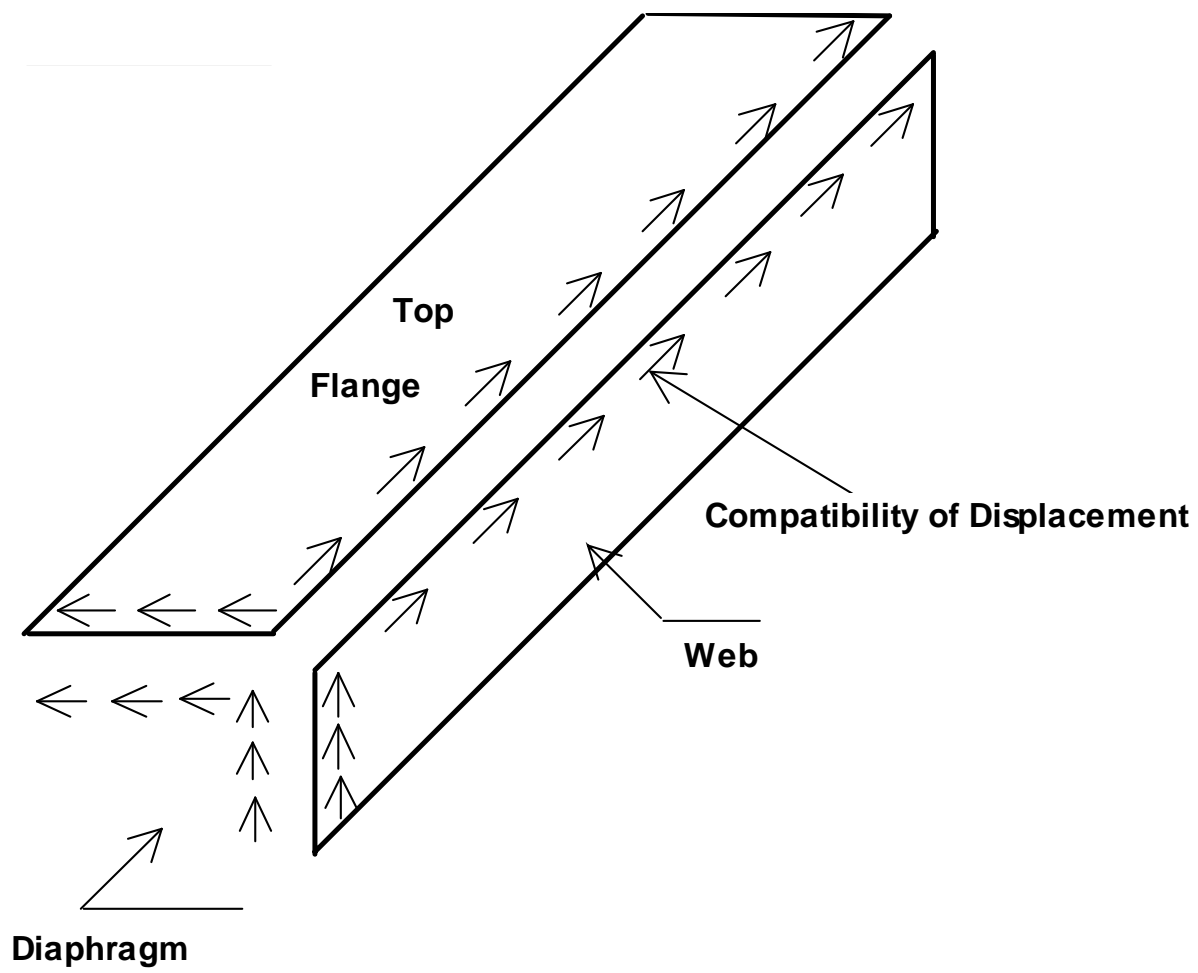

Figure 2. Imposed displacement constraint
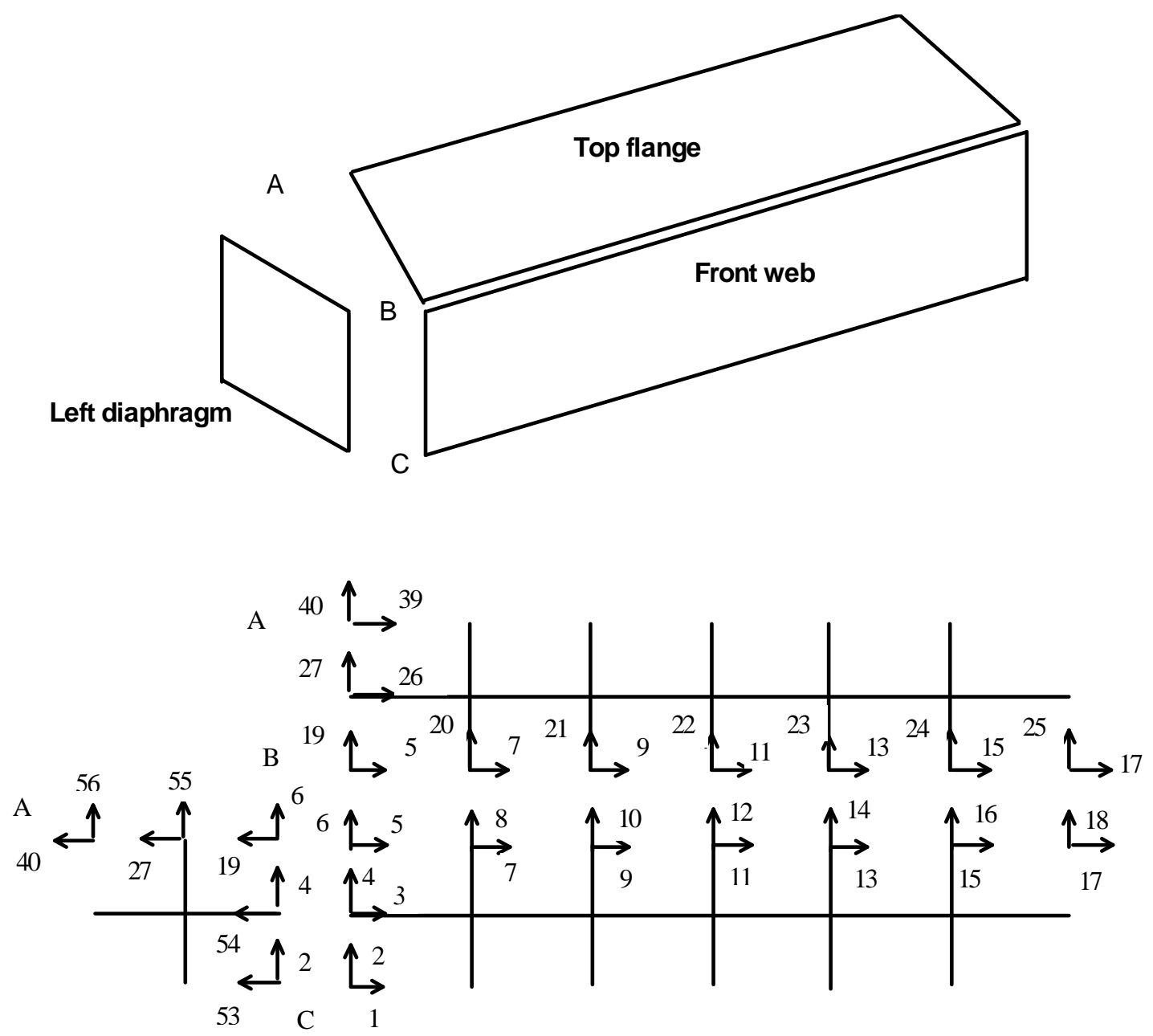

Figure 3. Freedom constraints 


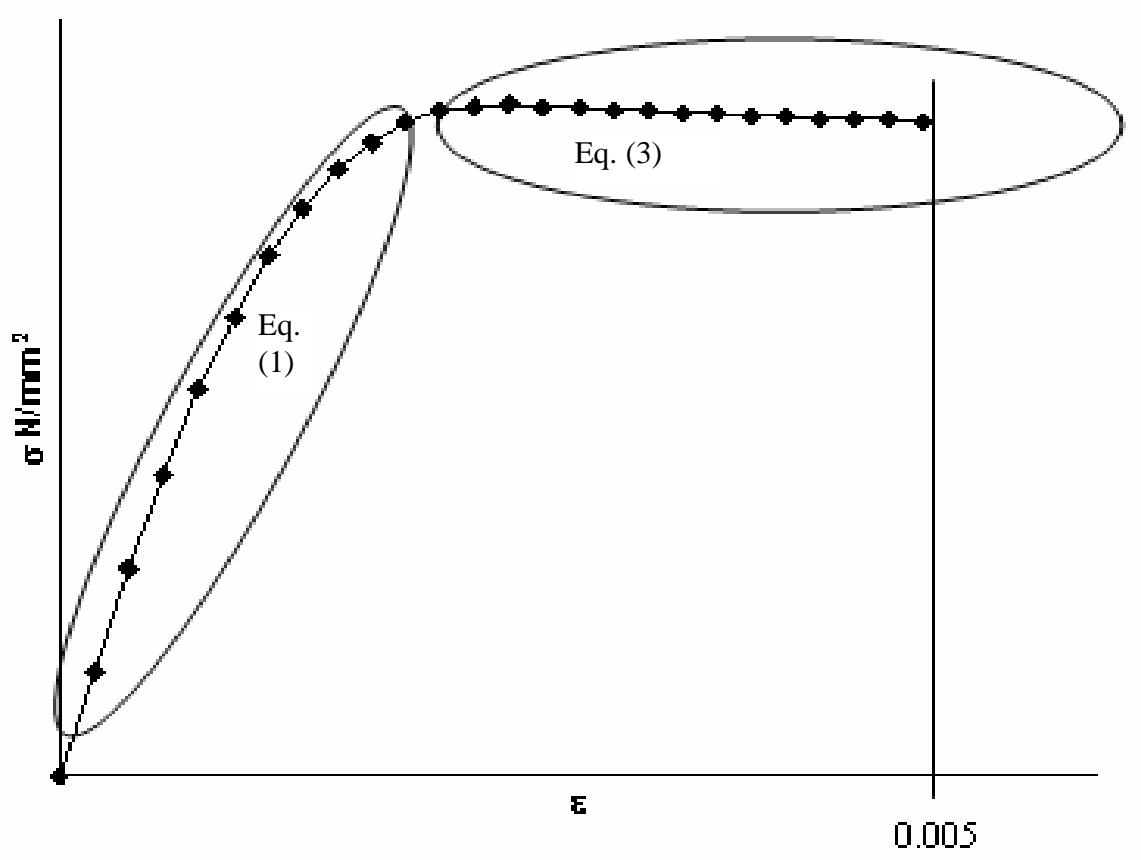

Figure 4. Typical combined stress-strain curve

material and after cracking the concrete remains a continuum but becomes orthotropic with one of the material axis orientated along the direction of the crack. The idea of orthogonal cracks was adopted, where cracks are allowed to open only in directions orthogonal to the existing cracks. These fixed orthogonal cracks are governed by the direction of the first principal (tensile) stress that exceeds the cracking strength. When a first crack occurs, it is assumed that direct tensile stresses cannot be supported in the direction normal to the crack and therefore, the modulus of elasticity corresponding to this direction (normal to crack) is reduced to zero unless tension stiffening is considered. The reduced shear stiffness due to aggregate interlock is accounted for by a reduced shear modulus of elasticity. On further loading, orthogonal cracks occur when the tensile stress parallel to the first cracks becomes greater than the concrete tensile strength $f_{t}$ (Alnuaimi, 1999; Kotsovos and Pavlovic, 1995; Chen and Saleeb, 1994; Abdel-Kader, 1993). The effect of the shear retention factor was considered as given by Eq. (4) while Eq. (5) was used for modelling the tension stiffening:

$$
\begin{aligned}
& \beta=0.4 \varepsilon_{c r} / \varepsilon_{n} \quad \geq 0.05 \\
& \sigma_{t}=\left(\sqrt[4]{\frac{\varepsilon_{C r}}{\varepsilon_{n}}}\right) f_{t}^{\prime} N / \mathrm{mm}^{2}
\end{aligned}
$$

Figure 5 shows typical shear retention curve and Fig. 6 shows tension stiffening curve used in this model. The program was based on the finite element displacement method, load control, where the displacements are the prime unknowns, with stresses being determined from the calculated displacement field. The non-linear problems were solved satisfying the basic laws of continuum mechanics: equilibrium, compatibility and constitutive relationship of materials. In this program, the continuum (structure) is divided into a series of distinct non-overlapping eight nodded 2D isoparametric elements with nine Gauss points for integration. Element stiffness matrix is given by Eq. (6).

$$
\left[K^{e}\right]=\int_{V_{e}}[B]^{T}[D][B] d V
$$

The summation of terms in Eq. (6) over all elements leads to the continuum stiffness matrix $[K]$. This is used in a system of equilibrium equations for complete continuum given by

$\{F\}=[K]\{\delta\}$

This system of equations is solved using direct Gaussian elimination algorithms in conjunction with frontal method of equation assembly and reduction to yield the nodal displacements. The main feature of this method is that it assembles the equations and eliminates the variable at the same time. Hence, the complete structural stiffness is never formed. This reduces computer storage significantly. Once this is done, the strains $\{\varepsilon\}$ and thereafter the 


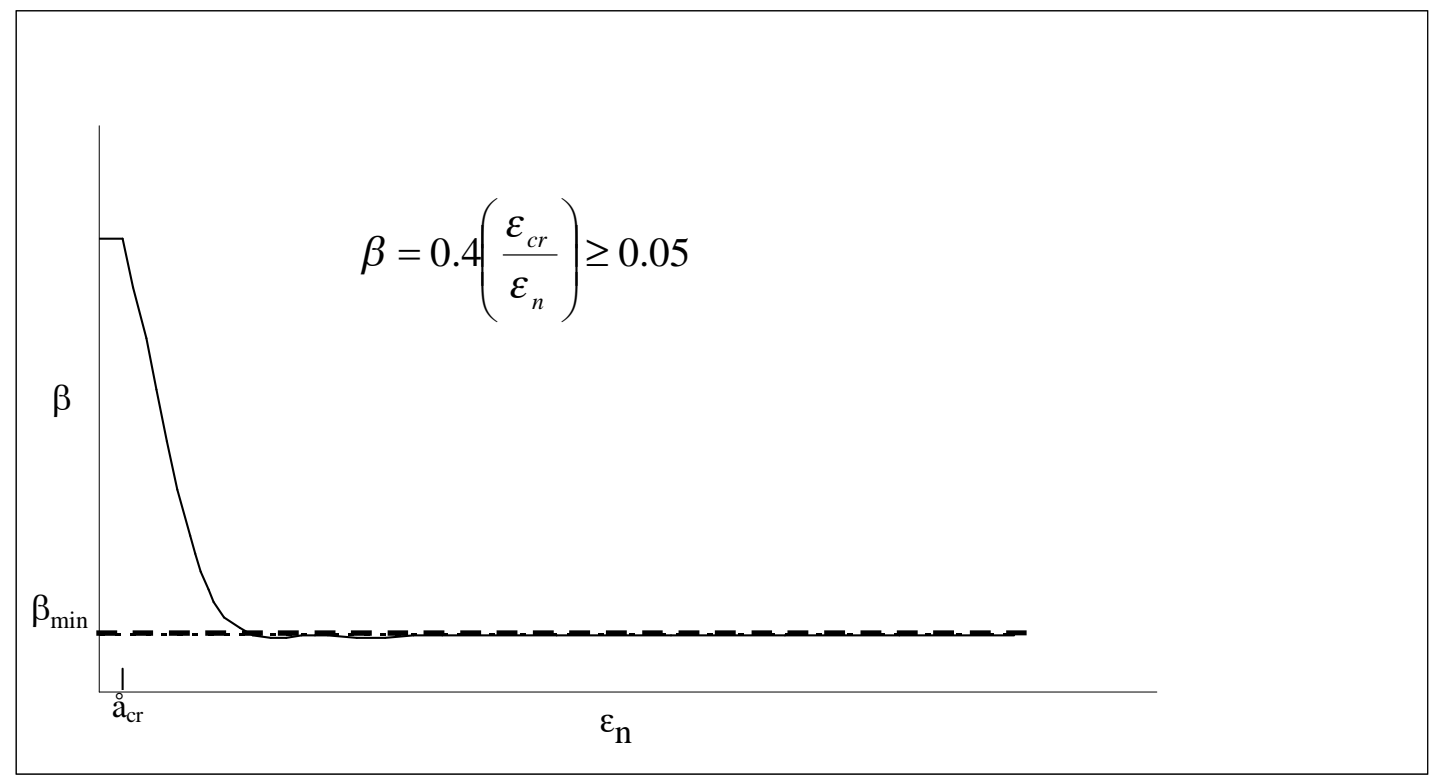

Figure 5. Shear retention curve

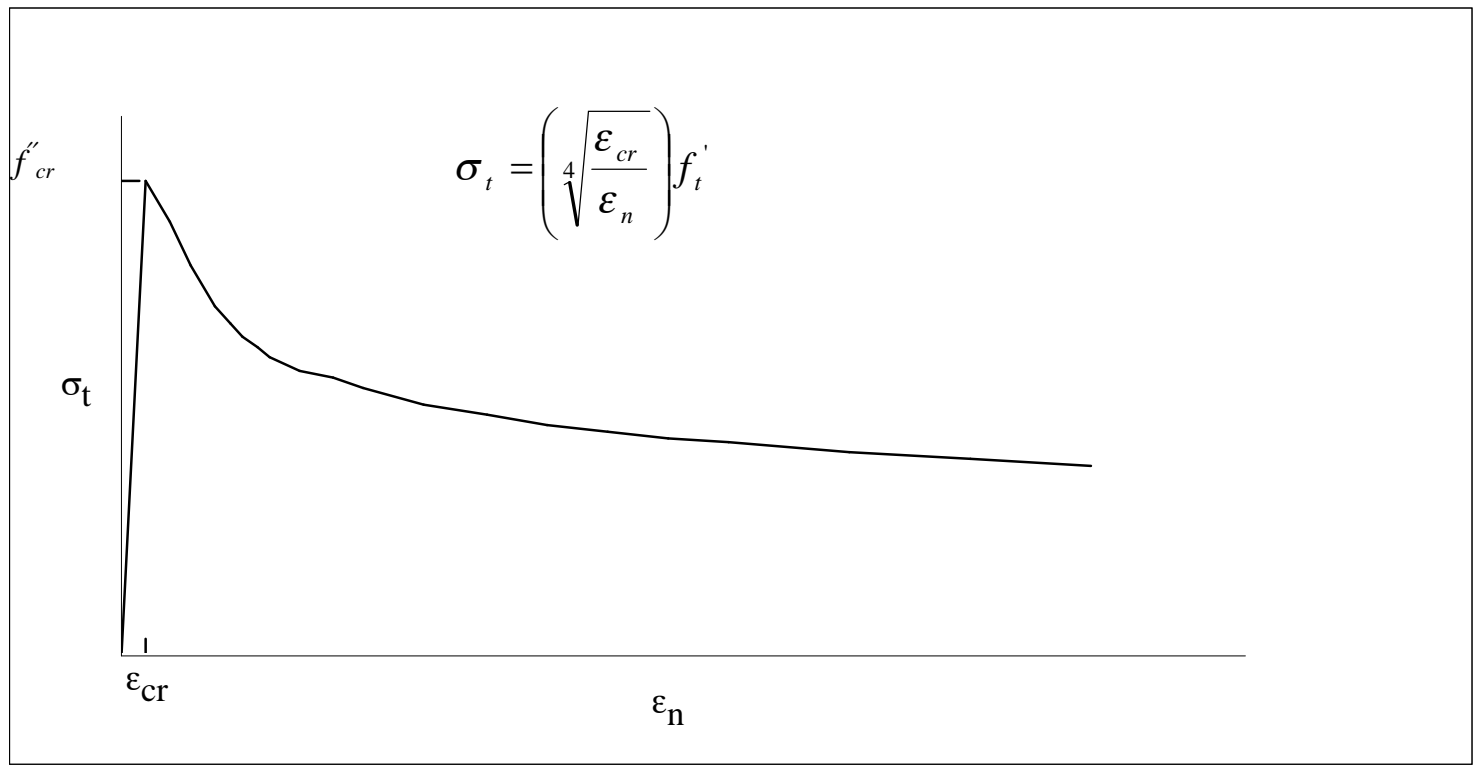

Figure 6. Tension stiffening curve 
stresses $\{\sigma\}$ in each element are evaluated using Eqs. (8) and (9) respectively

$$
\{\varepsilon\}=[B]\left\{\oint^{e}\right\}
$$

$$
\{\sigma\}=[D]\{\varepsilon\}
$$

Incremental iterative procedure with Modified NewtonRaphson method was used for the numerical solution of the non-linear problems. In this approach, the total load is divided into a number of load increments and the solutions are obtained iteratively until equilibrium is achieved to an acceptable level of accuracy. For every increment the stiffness matrix was updated at the first iteration. To ensure adequate convergence to the exact solution, continuity of displacement between adjoining elements, material constitutive relation as well as equilibrium are maintained by constraints on nodal points and ensuring that at any load level, stresses are consistent with displacement field and material constitutive relationship. This is obtained by successive linear solutions until specified accuracy is reached. If the material is within the elastic region, the relationship between the nodal forces and the displacement is linear and the stiffness matrix is unchanged. However, if the material yields then the relationship is non-linear and the stiffness matrix has to be updated. This is done by a succession of linear approximations considering the new material law. This piece-wise linearization is used to form a global non-linear solution for the problem.

A yield criterion for biaxial stress conditions based on non-dimensionalised values of the principal stresses $\sigma_{1}$ and $\sigma_{2}$ with respect to the uniaxial cylinder strength of concrete $f_{c}^{\prime}$ ' was adopted. This criterion was originally proposed by Kupfer et al. (1969) and tested and used by many researchers. Detailed derivations of compressioncompression, compression-tension and tension-tension criteria can be found in many references (i.e. Alnuaimi, 1999; Kotsovos and Pavlovic, 1995; Chen and Saleeb, 1994; Kupfer et al. 1969).

To ensure gradual elimination of out-of-balance (residual) forces and to terminate the iterative process when the desired accuracy has been achieved, a convergence criterion based on the out-of-balance load norms was used. Since it is difficult and expensive to check the decay of residual forces for every degree of freedom, an overall evaluation of convergence was used. This was done by using the residual force norm in each iteration $i$. This criterion assumes that convergence is achieved if:

$$
\frac{\Delta R_{i}^{*}}{F_{i}^{*}} \leq 0.04
$$

Where the norm of residuals $\Delta R_{i}^{*}$ at each iteration $i$, is given by Eq. (11)

$$
\Delta R_{i}^{*}=\sqrt{\left\{R_{i}\right\}^{T}\left\{R_{i}\right\}}
$$

And the norm of the applied loads $F_{i}^{*}$ is given by Eq. (12)

$$
\left.F_{i}^{*}=\sqrt{\left\{F_{i}\right\}^{T}\left\{F_{i}\right.}\right\}
$$

When a reinforced concrete member is subjected to a tensile stress exceeding its tensile strength, the concrete cracks at discrete locations. The total force is then transferred across the crack by the tensile steel. The reinforcing bars were modelled as embedded in orthogonal directions. Perfect bond (full compatibility) between steel and concrete was assumed. The displacement of any point on the bar was obtained from the displacement field of the isoparametric element in the bar direction. The stiffness matrix of the bar $K_{s}$ was calculated separately and then added to the stiffness matrix of the concrete $K_{c}$ to form the element stiffness matrix Eq. (13)

$$
K_{e}=K_{c}+K_{s}
$$

In addition, the following parameters were used as constants:

- Concrete cube compressive strength: $f_{c u}$ as measured for each beam.

- Concrete cylinder compressive strength:

$$
f_{c}^{\prime}=0.8 f_{\text {сu }} \mathrm{N} / \mathrm{mm}^{2} \text {. }
$$

- Young's modulus: $E_{c}=5000 \sqrt{f_{c}^{\prime}} N / \mathrm{mm}^{2}$.

- Compressive strain at peak stress: $\varepsilon_{c c}=\frac{\sqrt{f_{c}^{\prime}}}{2500}$.

- Maximum compressive strain: $\varepsilon_{\max }=0.0035$.

- Tensile strength of concrete: $f_{t}^{\prime}=0.54 \sqrt{f_{c}^{\prime}}$ $\mathrm{N} / \mathrm{mm}^{2}$.

- Mesh size: 84x84mm.

- Maximum number of load increments: 30.

- Maximum number of iteration s per increment: 100.

- Load increment: $10 \%$ for the first five increments and 5\% thereafter.

- Steel strain points for comparison with experimental results were located as in the actual beam.

\section{Validation of the Proposed Model}

The program was used in a parametric study for the analysis of eight hollow reinforced concrete beams tested at the University of Glasgow, UK (Alnuaimi, 1999; Alnuaimi, 2002; Alnuaimi, 2003) under combined bend- 
ing, shear and torsion. The main variables studied were the ratios of twisting moment to bending moment which varied between 0.19 to 2.62 and the ratio of shear stress due torsion to shear stress due shear which varied from 0.59 to 6.84 as shown in Table 2 .

\subsection{Test Beams}

The tested beams were $300 \times 300 \mathrm{~mm}$ cross section with 200x200 mm hollow core and $3800 \mathrm{~mm}$ length. The outer $400 \mathrm{~mm}$ of each end was filled with concrete to make it solid to form a diaphragm to prevent distortion. The beams were subjected to bending moment, twisting moment and shear force. The middle $1200 \mathrm{~mm}$ of the beam was considered as test span. This is the region where both maximum moment and shear occur and with least effect of concentrated stresses near the ends. Figure 7 shows loading and support arrangement and Fig. 8 shows close look of the torsional arm and concrete filled end of beam diaphragm. The beam was simply supported by a set of two perpendicular rollers at each support to allow axial displacement and rotation about a horizontal axis at the soffit of the beam Fig. 9. Bending and shear were direct result of mid-span point down-ward load while constant torsion was applied by means of the torsion arms. During testing the load was applied in increments as a percentage of the design load, $\mathrm{L}_{\mathrm{d}}, 10 \%$ for the first three increments, in anticipation of crack initiation, and then $5 \%$ until failure. The beam was considered to have collapsed when it could resist no more loads. Table 1 shows average measured material properties. Figure 10 shows the reinforcement provided along the test span of each beam. The solid circles refer to bars on which strain gauges were stuck while the hollow ones refer to bars without strain gauges installed.

\subsection{Comparison between Experimental and the $2 D$ Computational Results}

Here some experimental and computational results are compared. The comparison was carried out using the following criteria:

* Load displacement relationship,

* Longitudinal steel strain,

* Transverse steel strain,

* Failure load,

* Crack pattern and mode of failure.

\subsubsection{Load-Displacement Relationship}

Figure 11 shows displacements at mid-span of the beam. It is clear from this figure that, in general, an acceptable agreement between experimental and computational results was achieved in most cases. It should be noted that in few cases, due to technical problems, it was not possible to record displacement readings just before failure (i.e. BTV6).

\subsubsection{Longitudinal Steel Strain}

Figure 12 shows that a very good agreement between experimental and computational results was obtained for longitudinal steel strains. The reported strain ratios were closest to the mid-span of the beam.

\subsubsection{Transverse Steel Strain}

Figure 13 shows that a very good agreement between experimental and computational results was obtained for transverse steel strains. The reported strain ratios were at the mid-depth of the beam section, closest to mid-span.

\subsubsection{Failure Load}

The ratios of experimental to computational failure

Table 1. Average measured material properties

\begin{tabular}{|c|c|c|c|c|c|}
\hline \multirow{2}{*}{$\begin{array}{c}\text { Beam No } \\
\text { Unit }\end{array}$} & $\mathbf{f}_{\mathrm{cu}}$ & $\mathbf{f}_{\mathbf{c}}$ & $\mathbf{f}_{\mathbf{y}}$ & $\mathbf{f}_{\mathbf{y v}}$ & Age \\
\cline { 2 - 6 } & $\mathbf{N} / \mathbf{m m}^{\mathbf{2}}$ & $\mathbf{N} / \mathbf{m m}^{\mathbf{2}}$ & $\mathbf{N} / \mathbf{m m}^{\mathbf{2}}$ & $\mathbf{N} / \mathbf{m m}^{\mathbf{2}}$ & $\mathbf{d a y s}$ \\
\hline BTV1 & 39 & 33 & 495 & 516 & 10 \\
\hline BTV2 & 37 & 24 & 490 & 472 & 7 \\
\hline BTV3 & 38 & 27 & 490 & 472 & 7 \\
\hline BTV4 & 42 & 33 & 480 & 472 & 7 \\
\hline BTV5 & 35 & 27 & 490 & 472 & 8 \\
\hline BTV6 & 35 & 28 & 490 & 472 & 7 \\
\hline BTV7 & 54 & 34 & 500 & 472 & 7 \\
\hline BTV8 & 53 & 36 & 500 & 472 & 8 \\
\hline Average & 41.6 & 30.2 & 492 & 477.5 & 7.6 \\
\hline
\end{tabular}




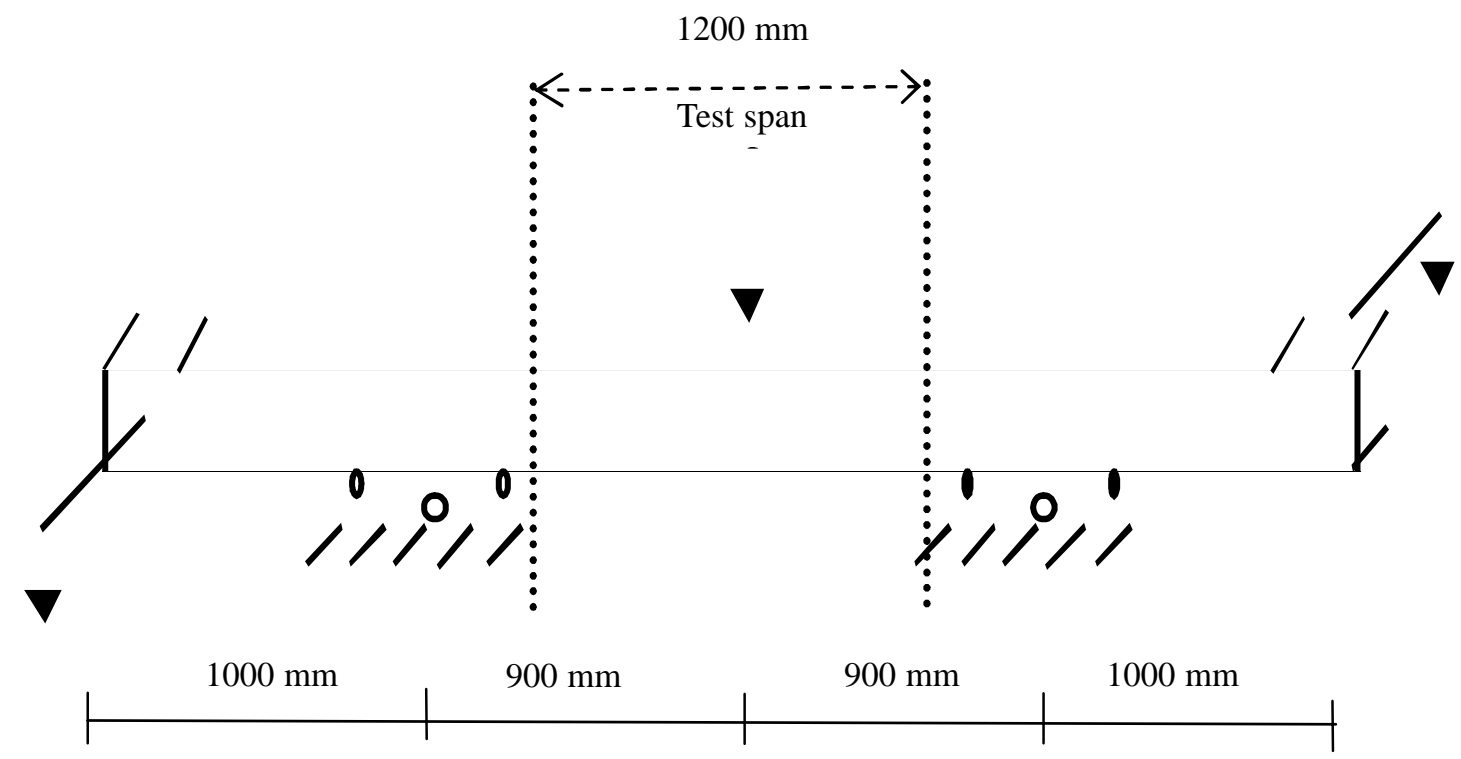

Figure 7. Loading and support arrangement

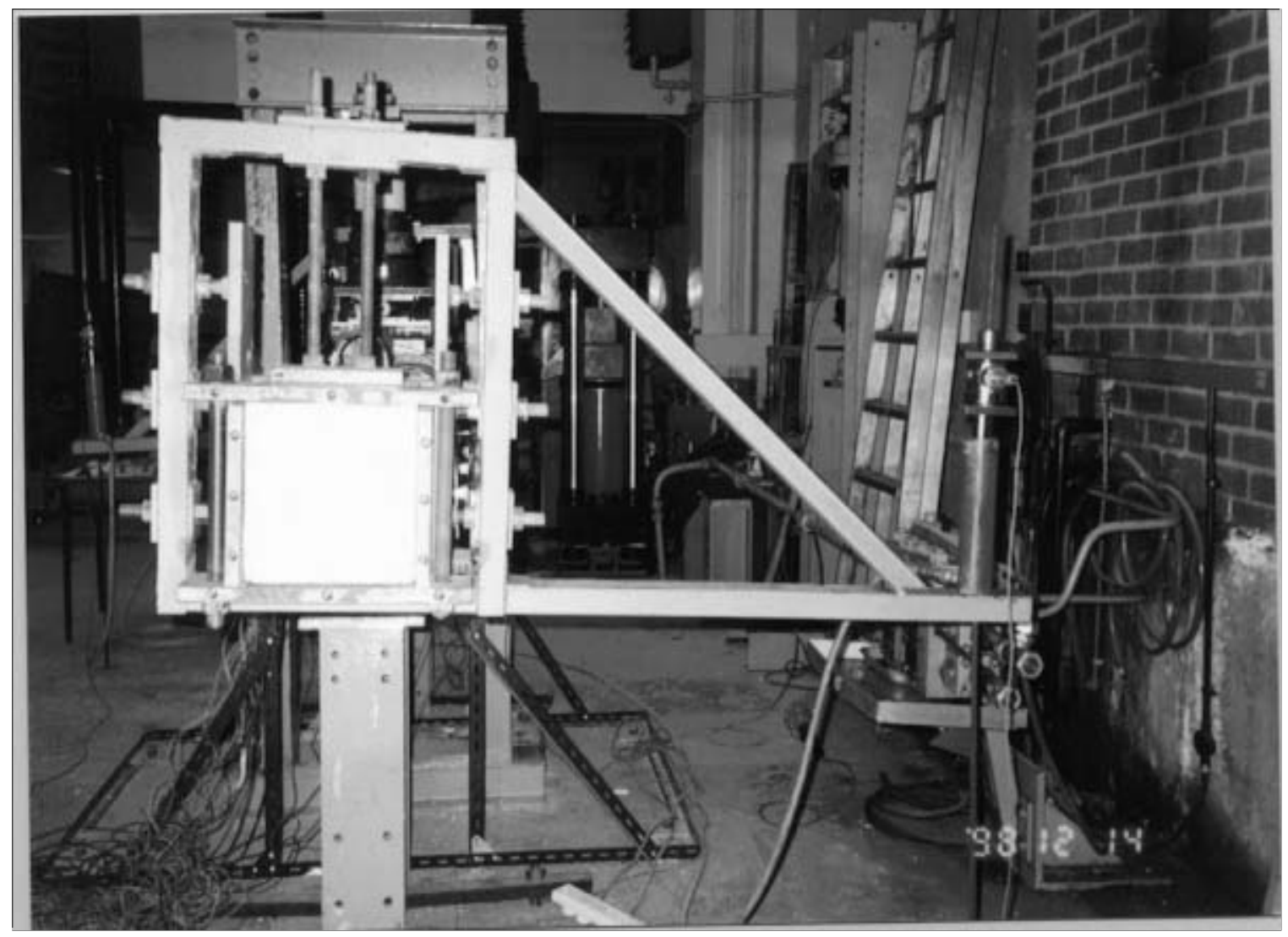

Figure 8. Torsion arm with a jack and load cell installed (see the solid end of the beam) 


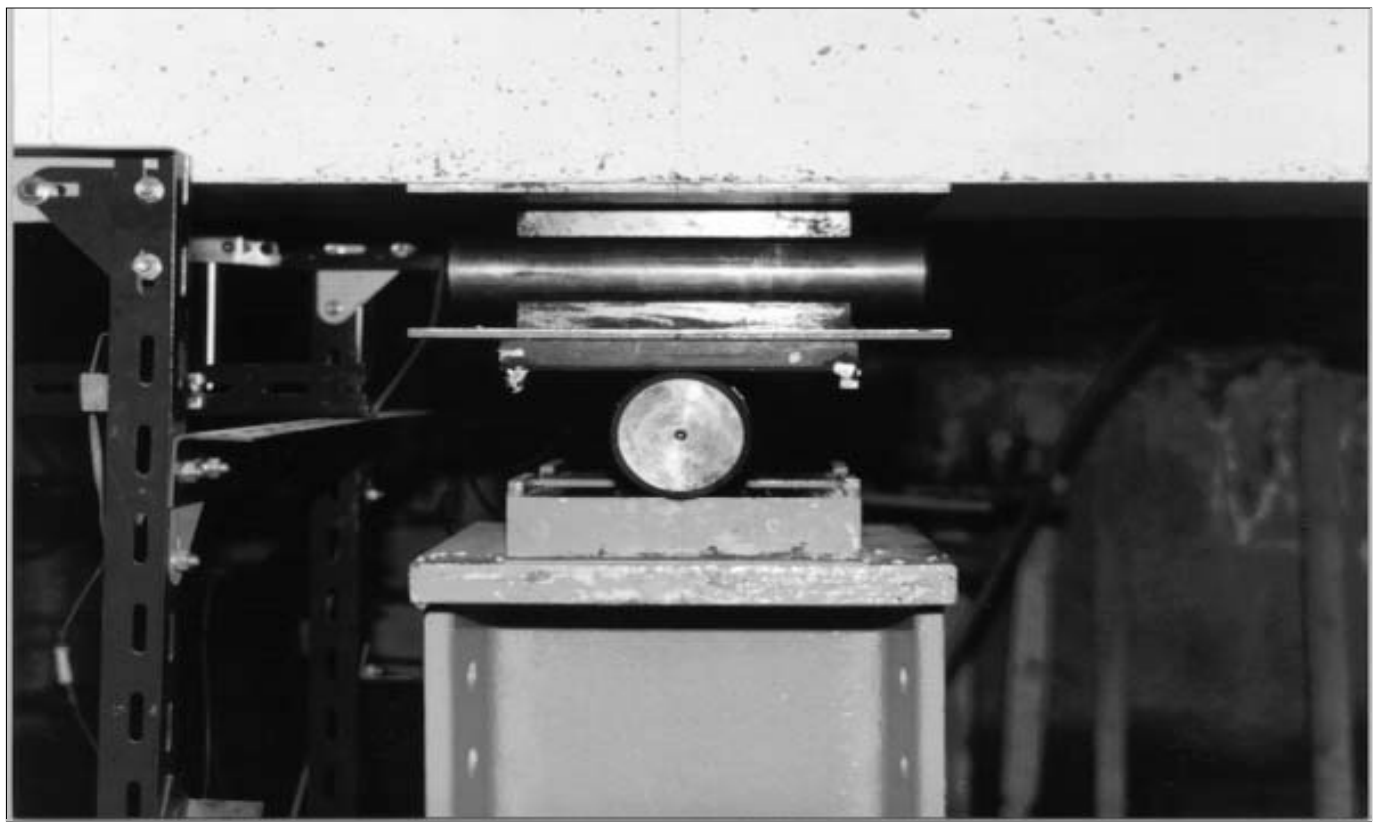

Figure 9. Set of perpendicular rollers

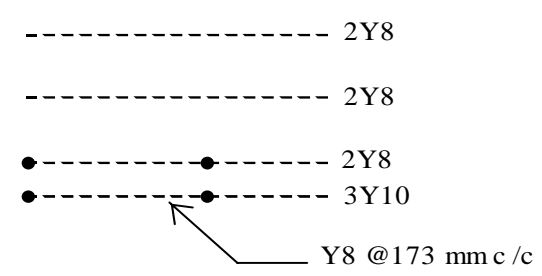

BTV1

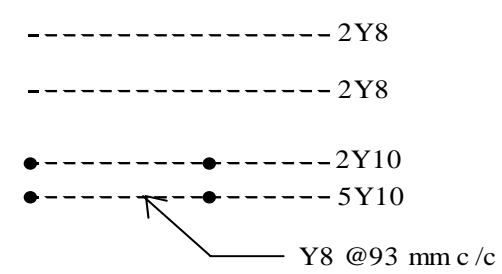

BTV3

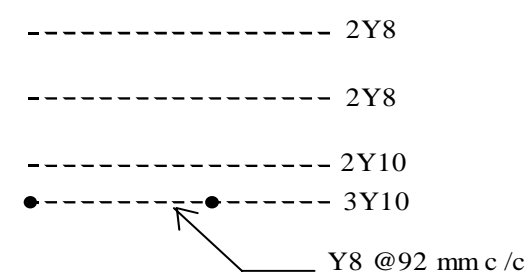

BTV5

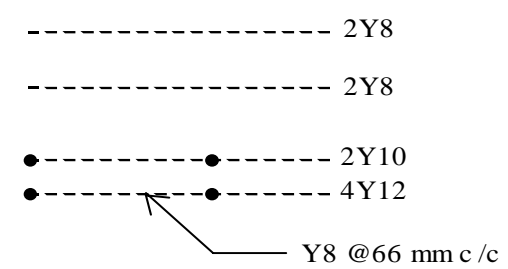

BTV7

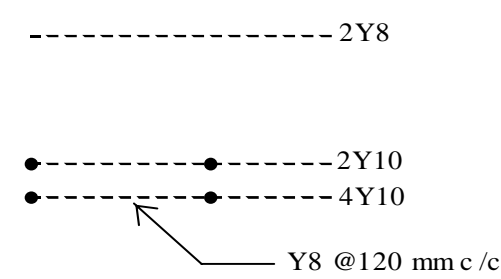

BTV2

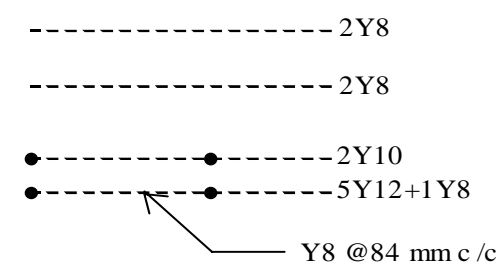

BTV4

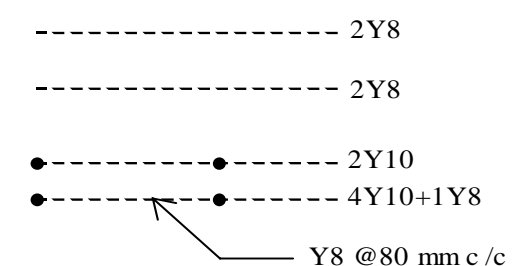

BTV6

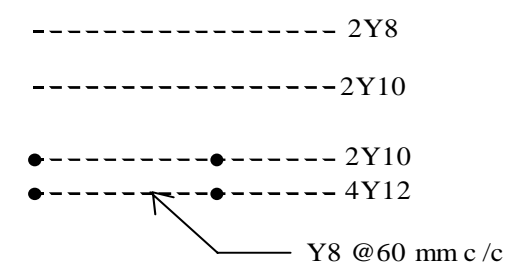

BTV8

Figure 10. Reinforcement provided in the test span 


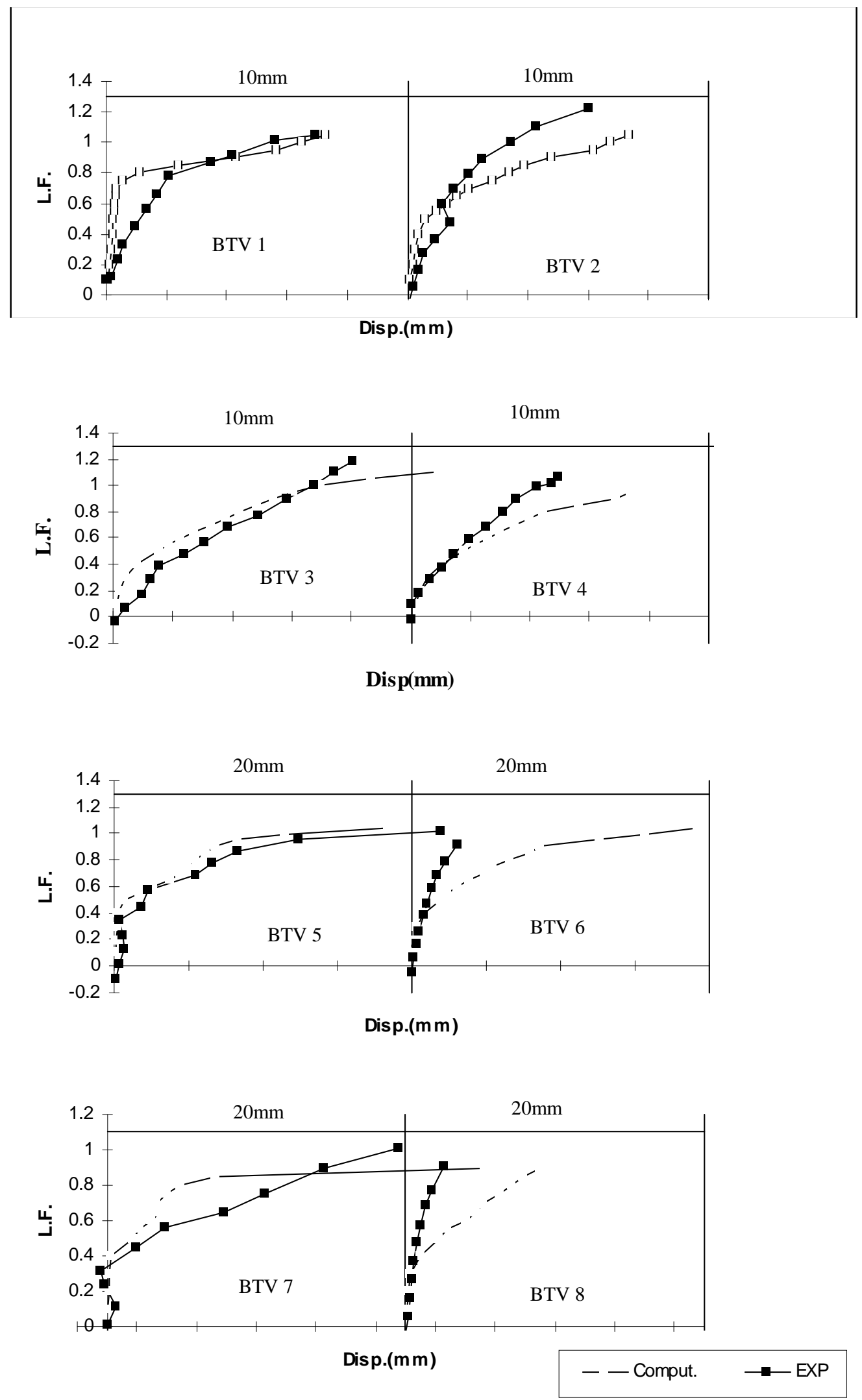

Figure 11. Vertical displacement at mid-span 
The Journal of Engineering Research Vol. 2, No. 1 (2005) 53-68

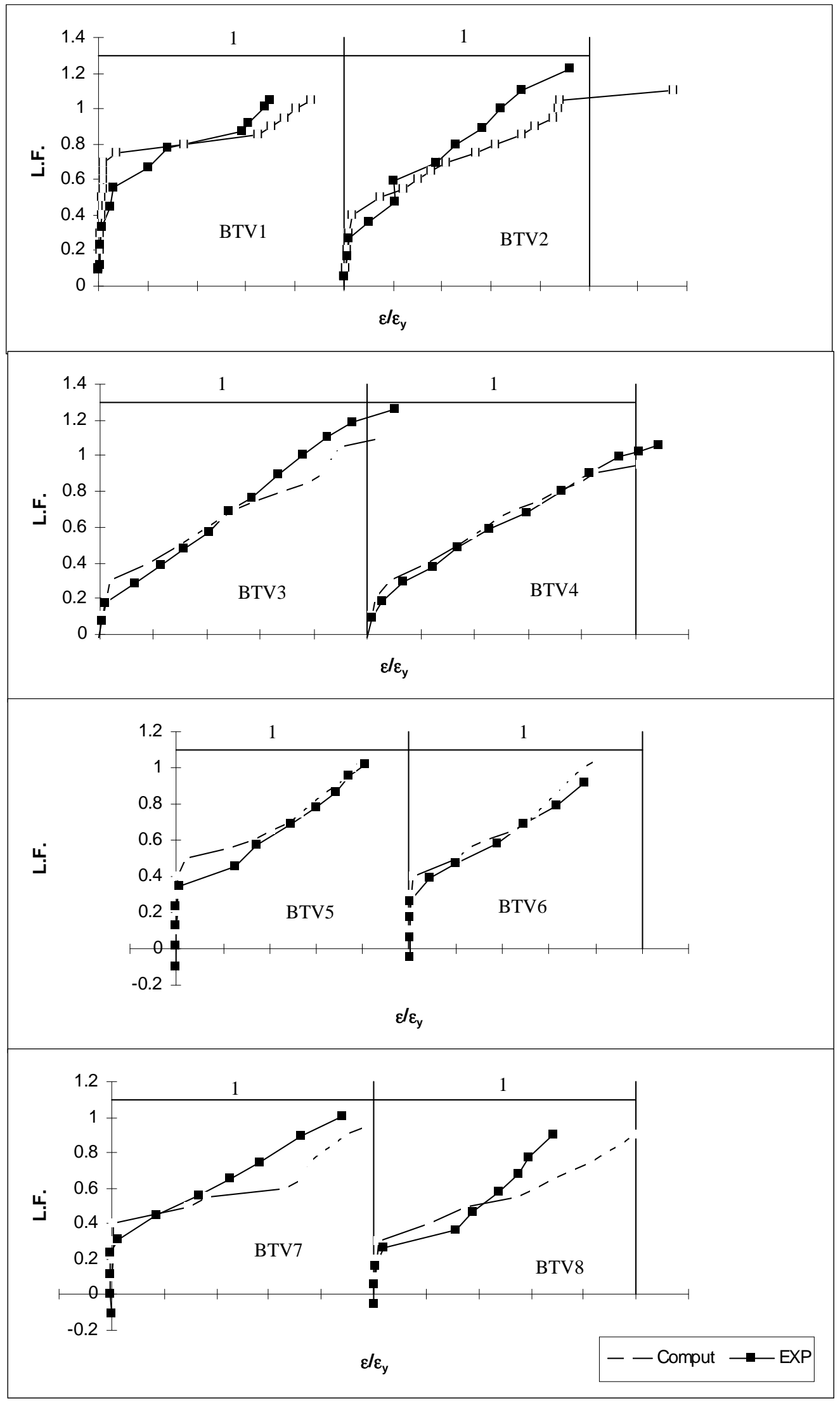

Figure 12. Longitudinal steel strain ratios 
The Journal of Engineering Research Vol. 2, No. 1 (2005) 53-68

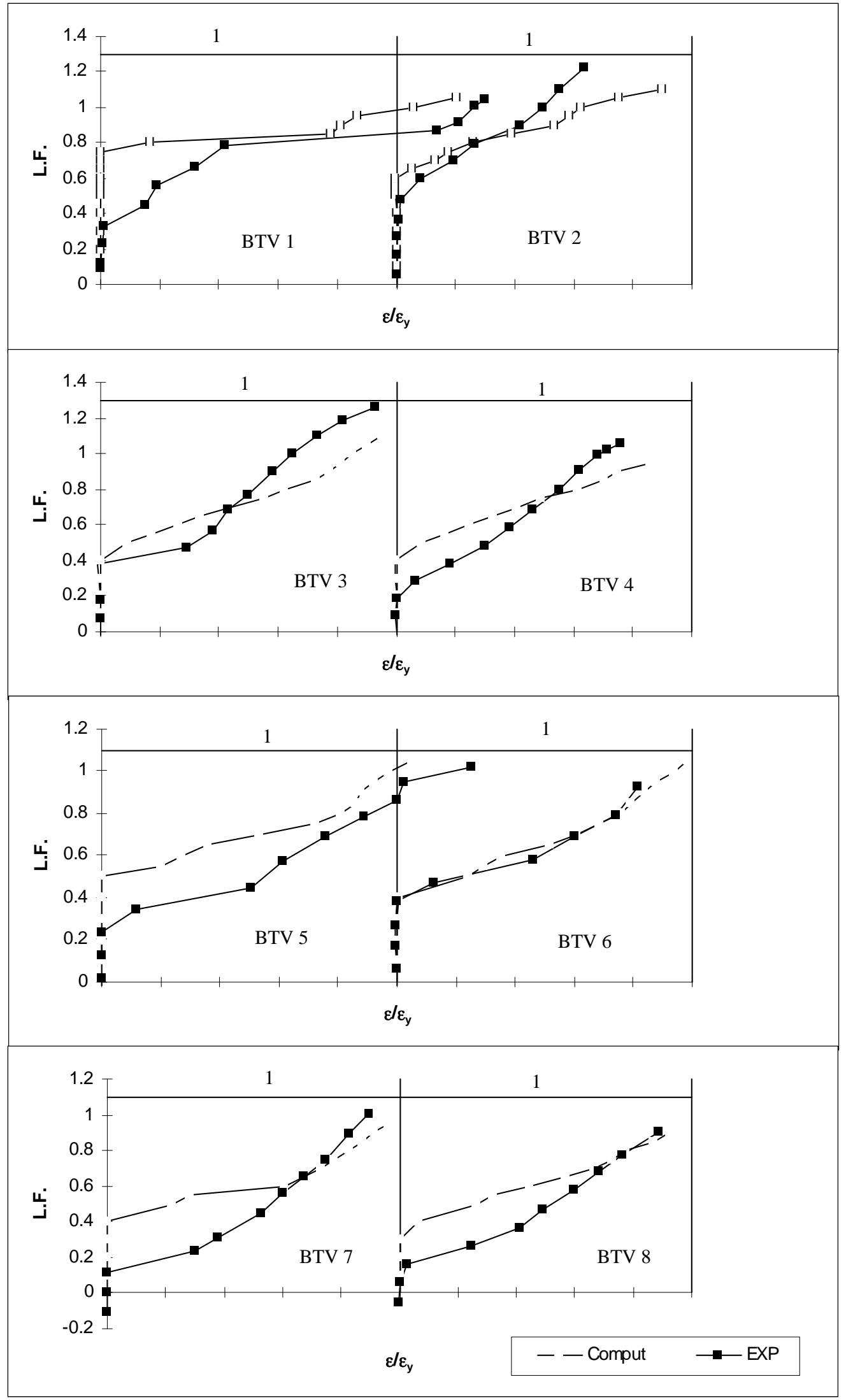

Figure 13. Transverse steel strain ratios 
loads $\mathrm{L}_{\mathrm{e}} / \mathrm{L}_{\mathrm{C}}$ are given in Table 2. A very good agreement was attained in failure loads. In most cases, the experimental results were slightly larger than the computed ones. Wide range of $\mathrm{T} / \mathrm{M}$ and $\tau_{\text {tor }} / \tau_{\text {shr }}$ ratios did not result in large differences between experimental and computational results. computed and observed crack patterns of the tested beams. The first graph in each pair represents the predicted location of cracks and their orientations in the test span just before failure load. It can be seen that a good agreement was achieved between the experimental and computational results on the crack concentration and orientation. All beams failed in a ductile manner as can be seen from

Table 2. Design, experimental and computed failure loads

\begin{tabular}{|c|c|c|c|c|c|c|}
\hline Beam & $\mathrm{T}_{\mathrm{d}}$ & $\mathrm{M}_{\mathrm{d}}$ & $\mathrm{V}_{\mathrm{d}}$ & $\mathrm{T}_{\mathrm{d}} / \mathrm{M}_{\mathrm{d}}$ & $\tau_{\text {tor }} / \tau_{\text {shr }}$ & $\mathrm{L}_{\mathrm{e}} / \mathrm{L}_{\mathrm{c}}$ \\
\hline No. & $\mathrm{kNm}$ & $\mathrm{kNm}$ & $\mathrm{kN}$ & Ratio & Ratio & Ratio \\
\hline BTV1 & 13 & 14.89 & 21.08 & 0.87 & 2.28 & 0.99 \\
\hline BTV2 & 13 & 32.89 & 41.08 & 0.4 & 1.17 & 1.1 \\
\hline BTV3 & 13 & 50.89 & 61.08 & 0.26 & 0.79 & 1.14 \\
\hline BTV4 & 13 & 68.89 & 81.08 & 0.19 & 0.59 & 1.12 \\
\hline BTV5 & 26 & 14.89 & 21.08 & 1.75 & 4.56 & 0.97 \\
\hline BTV6 & 26 & 32.89 & 41.08 & 0.79 & 2.34 & 0.88 \\
\hline BTV7 & 39 & 14.89 & 21.08 & 2.62 & 6.84 & 1.06 \\
\hline BTV8 & 39 & 32.89 & 41.08 & 1.19 & 3.51 & 1.01 \\
\hline
\end{tabular}

\subsubsection{Crack pattern and Mode of Failure}

When the principle tensile stress at any point in the structure exceeds the maximum tensile strength of the concrete a crack is initiated perpendicular to the direction of the principle tensile stress. Figure 14 shows typical figures on displacements and steel ratios (Figs. 11 - 13). Steel yielded in most cases or reached near yield before the concrete crushed. The load was transferred from the concrete to steel at about 35\% of failure load. Enough fine cracks have developed in each case long before major cracks development near the failure load.
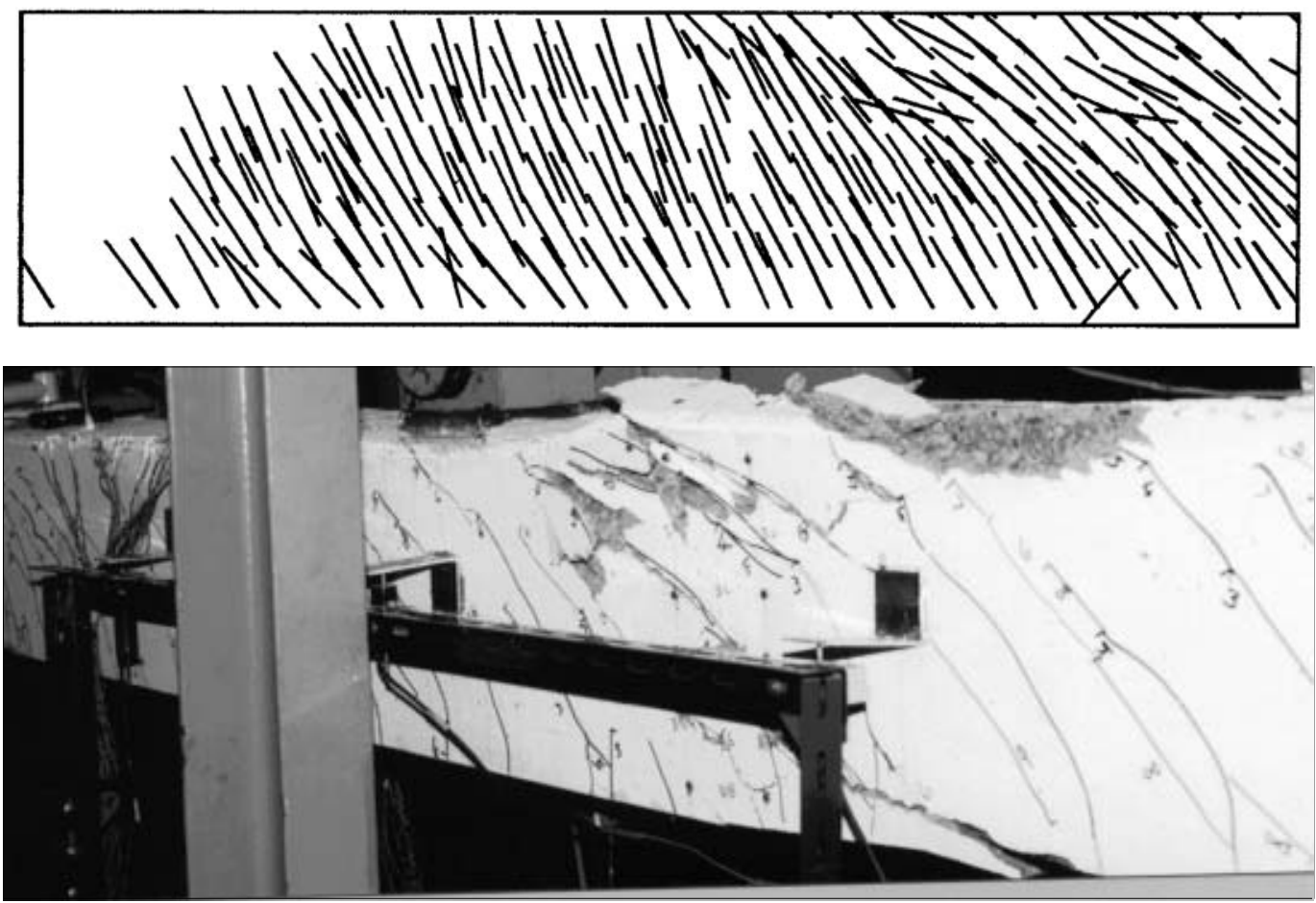

Figure 14a. Computed and observed crack development in the back web (BTV1) 

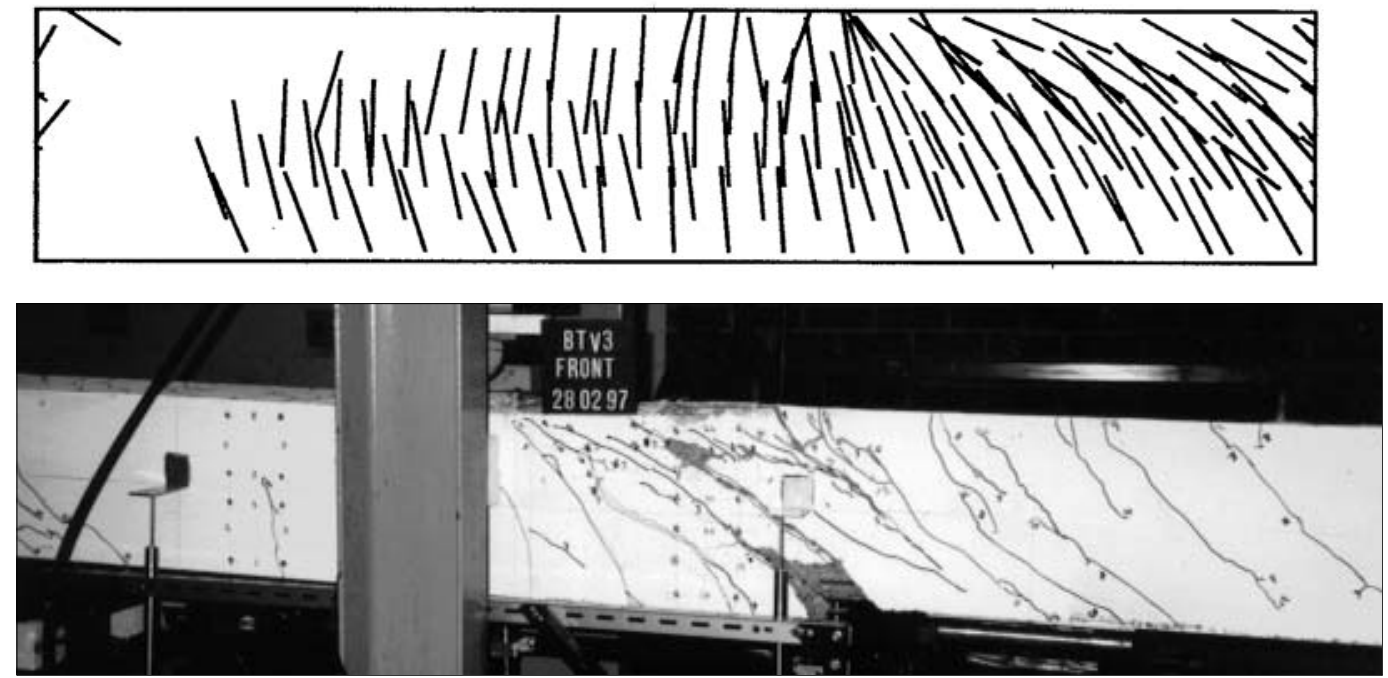

Figure 14b. Computed and observed crack development in the front web (BTV3)
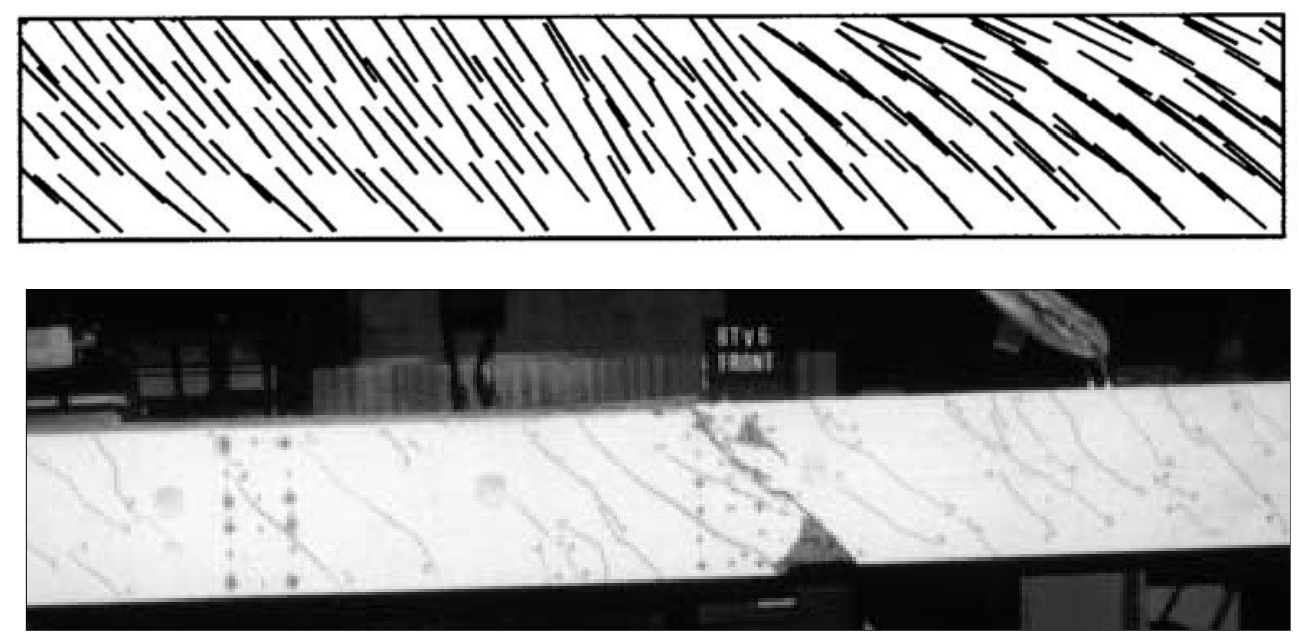

Figure 14c. Computed and observed crack development in the front web (BTV6)
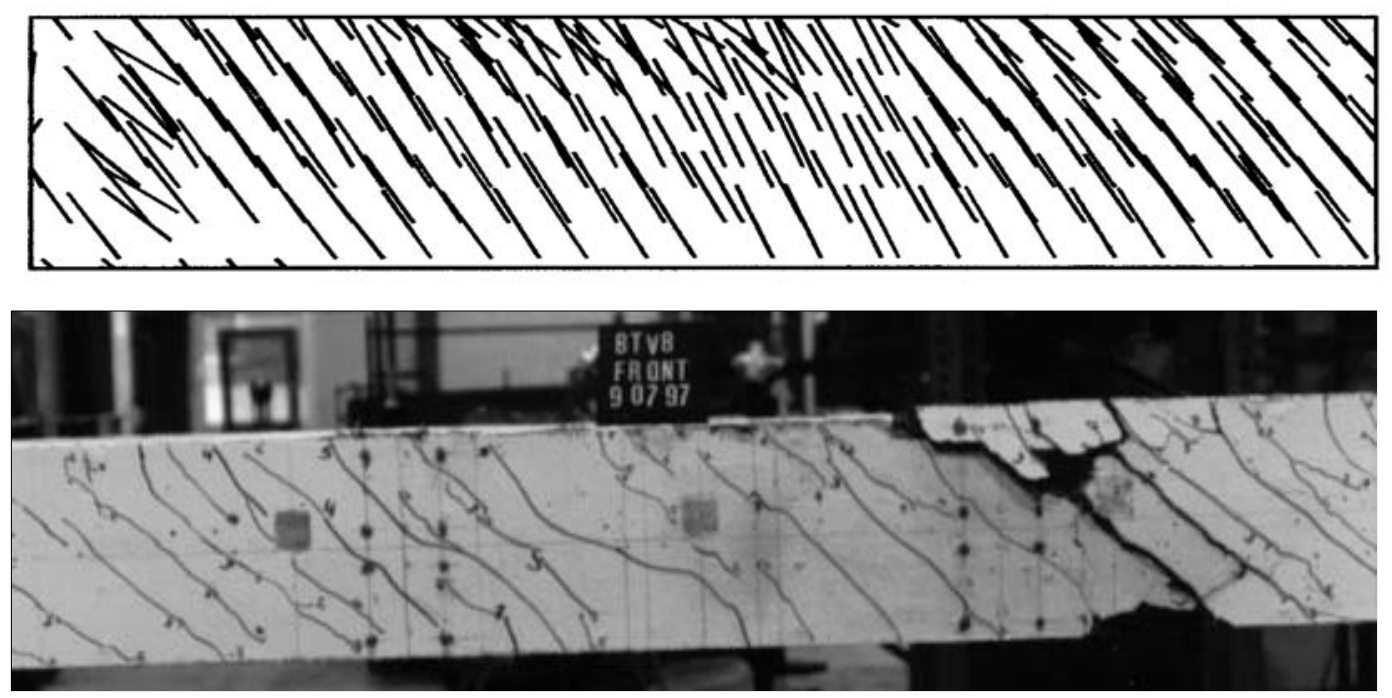

Figure 14d. Computed and observed crack development in the front web (BTV8) 


\section{Conclusions}

From the results presented in this paper, it can be concluded that the 2-D idealisation of hollow beams using plane elements is adequate for cross-sections with inplane stresses. The 2-D in-house finite element program used for the non-linear analysis gave good results when compared with experimental ones. Wide range of ratios of torsion to bending, $\mathrm{T} / \mathrm{M}$, and shear stress due to torsion to shear stress due to shear force, $\tau_{\text {tor }} / \tau_{\text {shr }}$, did not result in large differences between experimental and computational failure loads.

\section{References}

Abdel-Kader, M.M.A., 1993, "Prediction of Shear Strength of Reinforced and Prestressed Concrete Beams by Finite Element Method," Ph.D. Thesis, University of Glasgow.

Alnuaimi, A.S., 1999, "Direct Design of Reinforced and Partially Prestressed Concrete Beams for Combined Torsion, Bending and Shear," Ph.D. thesis, University of Glasgow, UK.

Alnuaimi, A.S., 2002, "Parametric Study on the Computational Behaviour of Hollow Beams Designed Using the Direct Design Method - Material Factors," Proceedings of High Performance Structures and Composites, Seville, Spain, WIT Press Publishers, March, pp. 605-614.

Alnuaimi, A.S., 2003, "Parametric Study on the Computational Behaviour of Hollow Beams Designed Using the Direct Design Method - Numerical Factors," Proceedings of International Conference on Advances in Structures, ASSCCA'03, Sydney, Australia, A.A., 22-25 June, Balkema Publishers, Vol. 2, pp. 1017 1021.
Bhatt P. and Abdelkader, M., 1995, "Prediction of Shear Strength of Reinforced Concrete Beams by Nonlinear Finite Element Analysis," Developments in Computational Techniques for Civil Engineering. CIVIL-COMP Press, Edinburgh, Scotland, UK. pp. 191-204.

Bhatt, P. and Beshara, A.W., 1980, "In-plane Stresses in End Diaphragms of Box Girder Bridges," Journal of the Institution of Engineers (India), Part CV; Civil Engineering Division; Sep. Vol. 61, pp. 103-109.

Chen, W.F. and Saleeb, A.F., 1994, "Constitutive Equations for Engineering Materials,” Elsevier Science B.V., Sara Burgerhartstraat 25, P.O. Box 211, 1000 AE Amesterdam, The Netherlands, p. 1129, ISBN: 0444884084.

Darwin, D. and Pecknold, D. A., 1977, "Nonlinear Biaxial Stress-Strain Law for Concrete," J. of the Engineering Mechanics Division, ASCE, Vol. 103 (EM2), April, pp. 229-241.

Kotsovos, M.D. and Pavlovic, M.N., 1995, "Structural Concrete,” Thomas Telford Publications. 1Heron Quay, London E14 4JD, UK, p. 550, ISBN: 0727720279.

Kupfer, H. Hilsdorf, H.K. and Rusch, H., 1969, "Behaviour of Concrete Under Biaxial Stresses," ACI Journal, August, pp. 656-666.

Liu T.C.Y., Nilson, A.H., and Slate, F.O., 1972, "StressStrain Response and Fracture of Concrete in Uniaxial and Biaxial Compression," ACI Journal, May, pp. 291295.

MacGregor, J.G. and Ghoneim, M.G., 1995, "Design for Torsion," ACI Structural J, No. 92-S20, Mar.- Apr., pp. 211-218.

Thurlimann, B., 1979, "Torsional Strength of Reinforced and Prestressed Concrete Beams-CEB Approach," Institut fur Baustatik und konstruktion, ETH. Zurich., No. 92. June, pp. 117-143. 